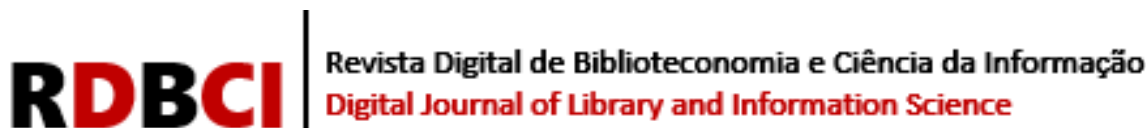

$\mathbf{I S T}_{1678-765 X}$

do)

10.20396/rdbci.v19ioo.8667199 (c) (i) $\mathrm{BY}$

ARTIGO

\section{Barreiras à informação em saúde nas mídias sociais}

\author{
Fellipe Sá Brasileiro1 (iD https://orcid.org/0000-0002-1158-8909 \\ Ana Margarida Pisco Almeida2 (iD) https://orcid.org/0000-0002-7349-457X \\ ${ }^{1}$ Universidade Federal da Paraíba, João Pessoa, PB, Brasil / e-mail: fellipesa@hotmail.com \\ 2 Universidade de Aveiro, Aveiro, Portugal / e-mail: marga@ua.pt
}

\begin{abstract}
RESUMO
Introdução: A utilização das mídias sociais para a autogestão de informações sobre saúde constitui uma prática recorrente dos usuários leigos que vivenciam diferentes contextos de saúde. Embora facilitem o acesso e o compartilhamento de informações, as mídias sociais podem contribuir para a criação de possíveis riscos à saúde e ao bem-estar, uma vez que ampliam as experiências de vulnerabilidade emocional e desinformação. Objetivo: Para descobrir as evidências atuais que impactam o uso benéfico das mídias sociais para fins de informação sobre saúde, buscou-se examinar como as barreiras à informação em saúde nas mídias sociais, percebidas pelos usuários leigos, são apresentadas em pesquisas empíricas recentes. Método: Realizou-se uma pesquisa qualitativa de caráter exploratório por meio de uma revisão da literatura na base de dados SCOPUS. Resultados: Observou-se que, embora sejam múltiplas e variem conforme os contextos de saúde e as motivações situacionais, as barreiras podem ser articuladas em uma malha composta pelas seguintes meta-barreiras: diaspóricas, desinformação, letramento, interação e emocionais. Conclusão: Conclui-se que a malha de barreiras apresentada, associada a outras barreiras estruturais, pode contribuir para a construção de instrumentos de pesquisa e intervenções digitais envolvendo o uso das mídias sociais para fins de informação sobre saúde.
\end{abstract}

PALAVRAS-CHAVE

Informação sobre saúde. Mídias sociais. Práticas informacionais. Barreiras de informação. Usuários.

\section{Barriers to health information on social media}

\begin{abstract}
Introduction: The use of social media for self-management of health information is a recurrent practice for lay users who experience different health contexts. While facilitating access and sharing of information, social media can contribute to the creation of possible risks to health and well-being, since they expand the experiences of emotional vulnerability and misinformation. Objective: To discover the current evidence that impacts the beneficial use of social media for health information purposes, we sought to examine how barriers to health information on social media, perceived by lay users, are presented in recent empirical research. Methodology: A qualitative exploratory research was carried out through a literature review in the SCOPUS database. Results: It was observed that, although they are multiple and vary according to the health contexts and situational motivations, the barriers can be articulated in a mesh composed of the following meta-barriers: diasporic, misinformation, literacy, interaction and emotional. Conclusion: It is concluded that the mesh of barriers presented, associated with other structural barriers, can contribute to the construction of research instruments and digital interventions involving the use of social media for health information purposes.
\end{abstract}

KEYWORDS

Health information. Social media. Information practices. Information barriers. Users. 


\section{Devista Digital de Biblioteconomia e Ciência da Informação Digital Journal of Library and Information Science}

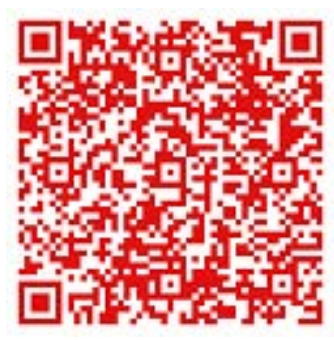

JITA: CB. User studies. 


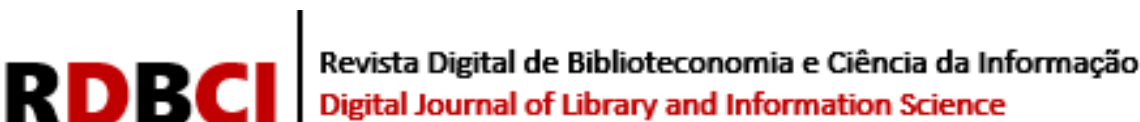

\section{INTRODUÇÃO}

O uso da mídia social como fonte de informações sobre saúde é crescente no cenário contemporâneo. É amplamente discutido na literatura que as plataformas de mídia social apresentam tanto benefícios quanto desvantagens para o autocuidado de saúde dos usuários leigos (DE MARTINO et al., 2017) (WANG et al., 2019). Os benefícios se relacionam às facilidades para encontrar, acessar, comparar e compartilhar informações. Já as desvantagens se relacionam às questões de credibilidade, qualidade, veracidade e sobrecarga das informações. Seja para refletir sobre benefícios ou desvantagens, os estudos sobre comunicação/informação/saúde nas mídias sociais tendem a focar uma perspectiva ligada aos aspectos usuais e materiais das plataformas, envolvendo, por exemplo, a disponibilidade pública, a facilidade de uso, o imediatismo de informações (AGARWAL; YILIYASI, 2010).

Contudo, compreender de modo integral o uso das mídias sociais como espaço de informações sobre saúde requer ir além da materialidade das plataformas. Requer desvelar as complexidades que envolvem os desafios e dilemas à autogestão das informações (BRASHERS et al., 2002) nas mídias sociais. Requer, portanto, integrar a materialidade aos contextos e situações (SCHATZKI, 2005). Nesse sentido, a abordagem das práticas informacionais (LLOYD, 2010), numa perspectiva de transição dos contextos de saúde (LLOYD, 2014), significativos e pessoais (CLEMENS; CUSHING, 2010), se configura relevante na medida em que permite pensar o contexto de saúde como uma experiência descolada das rotinas estáveis (CLEMENS; CUSHING, 2010) - de ruptura das bases de informação e, ao mesmo tempo, de (re) construção de novas bases de informação (LLOYD, 2014). Nessa perspectiva transitória, as tensões relacionadas ao uso das mídias sociais se imbricam com as tensões que emergem do contexto vivenciado, produzindo experiências informacionais ambivalentes e desconhecidas.

Considerando que essas tensões envolvem múltiplos objetivos, recursos e imposições/padrões, uma estratégia alternativa para desvelar os desafios e dilemas acerca do uso das mídias sociais para fins de informação sobre saúde pode ser a análise das barreiras informacionais. As barreiras informacionais, de acordo com Araújo (2021), "são inerentes ao fenômeno informacional, pois são relativas ao sujeito informacional e suas habilidades para determinar suas necessidades informacionais, bem como, desenvolver buscas e usos efetivos da informação num contexto de competências informacionais precárias e ambientes complexos e adversos”. Nesse sentido, na dimensão da experiência, as barreiras informacionais podem se configurar como elemento analítico objetivo que permite revelar questões complexas que envolvem os diferentes contextos e situações de saúde, como, por exemplo, os múltiplos objetivos conflitantes que uma situação pode apresentar (GOLDSMITH, 2001). Embora as barreiras sejam indicadas como elemento de análise para os estudos sobre cuidados de saúde envolvendo as mídias sociais (ANTHEUNIS et al., 2013), observa-se a necessidade de um aprofundamento do entendimento relacional dessas barreiras, que seja capaz de abranger a articulação entre os usos das mídias sociais e as tensões inerentes à transição dos contextos.

Acredita-se que tanto a identificação quanto a articulação das barreiras informacionais vinculadas às mídias sociais, percebidas pelos usuários que vivenciam ou enfrentam tensões transitórias em seus contextos de saúde, podem contribuir para o desenvolvimento de estudos e/ou intervenções relacionados à promoção da resiliência informacional (LLOYD, 2014; LLOYD, 2015; BRASILEIRO, 2020) e à regulação das práticas de autogestão de informações sobre saúde (BRASHERS et al., 2002). Nessa direção, portanto, a abordagem das práticas informacionais (LLOYD, 2014; LLOYD, 2010), numa perspectiva situacional, pode favorecer o desenvolvimento de um enquadramento original acerca das barreiras informacionais vinculadas às mídias sociais, de modo articulado com a perspectiva de transição contextual. 


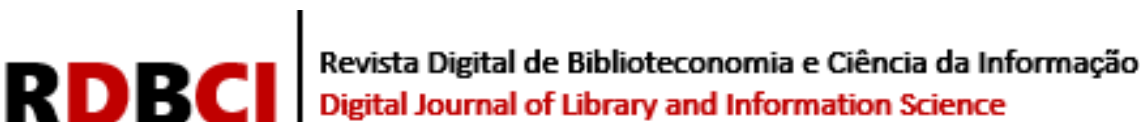

A partir destas reflexões iniciais, com o objetivo de examinar como podem se configurar as barreiras à informação em saúde nas mídias sociais, que impactam as práticas de autogerenciamento das informações sobre saúde, efetuou-se uma revisão de pesquisas empíricas contemporâneas, indexadas em base de dados internacional, que exploram a utilização das mídias sociais para fins de informação na perspectiva dos usuários leigos que vivenciam contextos de saúde diversos. A partir desta revisão é possível desenvolver um enquadramento analítico para estudos futuros. Assim, tratamos como escopo da revisão as seguintes dimensões específicas: as barreiras ou dificuldades percebidas pelos sujeitos das pesquisas; as motivações desses sujeitos quanto ao uso das mídias sociais para fins de informação em saúde; as mídias sociais relacionadas; e os contextos de saúde vivenciados.

\section{MÉTODOS}

A estratégia de pesquisa desta revisão de literatura segue orientações do modelo PRISMA (MOHER et al., 2009). A pesquisa ocorreu na plataforma de dados científicos SCOPUS, por se tratar de um banco de dados internacional abrangente, que envolve resumos e citações de trabalhos em diversas áreas do conhecimento. O recorte temporal contemplou os registros publicados entre 2015 e 2020. O protocolo de pesquisa envolveu os seguintes termos: barriers OR restrictions OR difficulties OR impediments AND health information OR health misinformation AND social media OR digital media OR social network OR online network.

A etapa de identificação dos registros considerou os seguintes critérios de seleção, disponíveis no próprio sistema da plataforma SCOPUS: (a) artigos científicos ou anais de conferência publicados nos últimos cinco anos; (b) textos publicados em inglês ou português. As etapas de triagem e elegibilidade envolveram a leitura de títulos e resumos com base nos seguintes critérios de inclusão: (a) estudos acerca das mídias sociais; (b) estudos acerca da informação em saúde; (c) estudos envolvendo barreiras à informação em saúde nas mídias sociais; (d) estudos que abordam a perspectiva de usuários leigos de informação em saúde; (e) estudos acerca do uso real de mídias sociais, decorrentes de pesquisas empíricas e originais.

Foram considerados os seguintes critérios de exclusão na etapa de leitura dos textos elegíveis: (a) estudos que não exploram as mídias sociais; (b) estudos que não exploram a informação em saúde; (c) estudos que não exploram as barreiras ou dificuldades à informação em saúde nas mídias sociais; (d) estudos relacionados à perspectiva dos profissionais de saúde; (e) estudos acerca de opiniões de especialistas ou entrevistas não decorrentes de métodos; (f) estudos que não tratam de pesquisas empíricas e originais, como revisões de literatura.

A etapa de avaliação dos estudos incluídos envolveu a leitura detalhada dos textos completos e considerou os seguintes elementos para a extração dos dados: (a) barreiras ou dificuldades à informação em saúde nas mídias sociais; (b) mídias sociais utilizadas pelos usuários para fins de informação em saúde; (c) motivações ou intenções dos usuários relacionadas ao uso das mídias sociais; (d) contextos de saúde dos usuários. Todas essas etapas do fluxo da pesquisa estão representadas na Figura 1, disponível na seção a seguir.

\section{RESULTADOS}

Foram identificados 4.268 estudos na base de dados SCOPUS (Figura 1). Após a remoção de 25 estudos duplicados, restaram 4.243 estudos para revisão. Desses, 1.882 foram excluídos após a aplicação dos critérios de seleção - ano (2015 a 2020), língua (Português ou Inglês), tipo de estudo (Artigos e Anais de Conferência). Após a triagem feita nos títulos e 


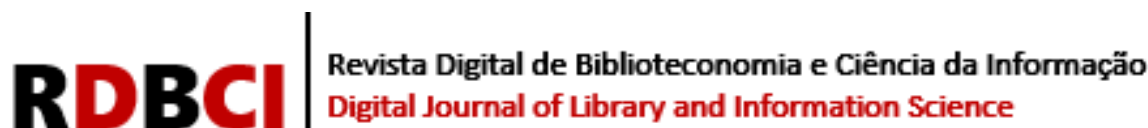

resumos com base nos critérios de inclusão e exclusão adotados, 38 estudos foram elegíveis para leitura completa. Desses, 27 foram descartados por estarem fora do escopo da pesquisa. Um total de 11 estudos completos foram incluídos para a revisão qualitativa.

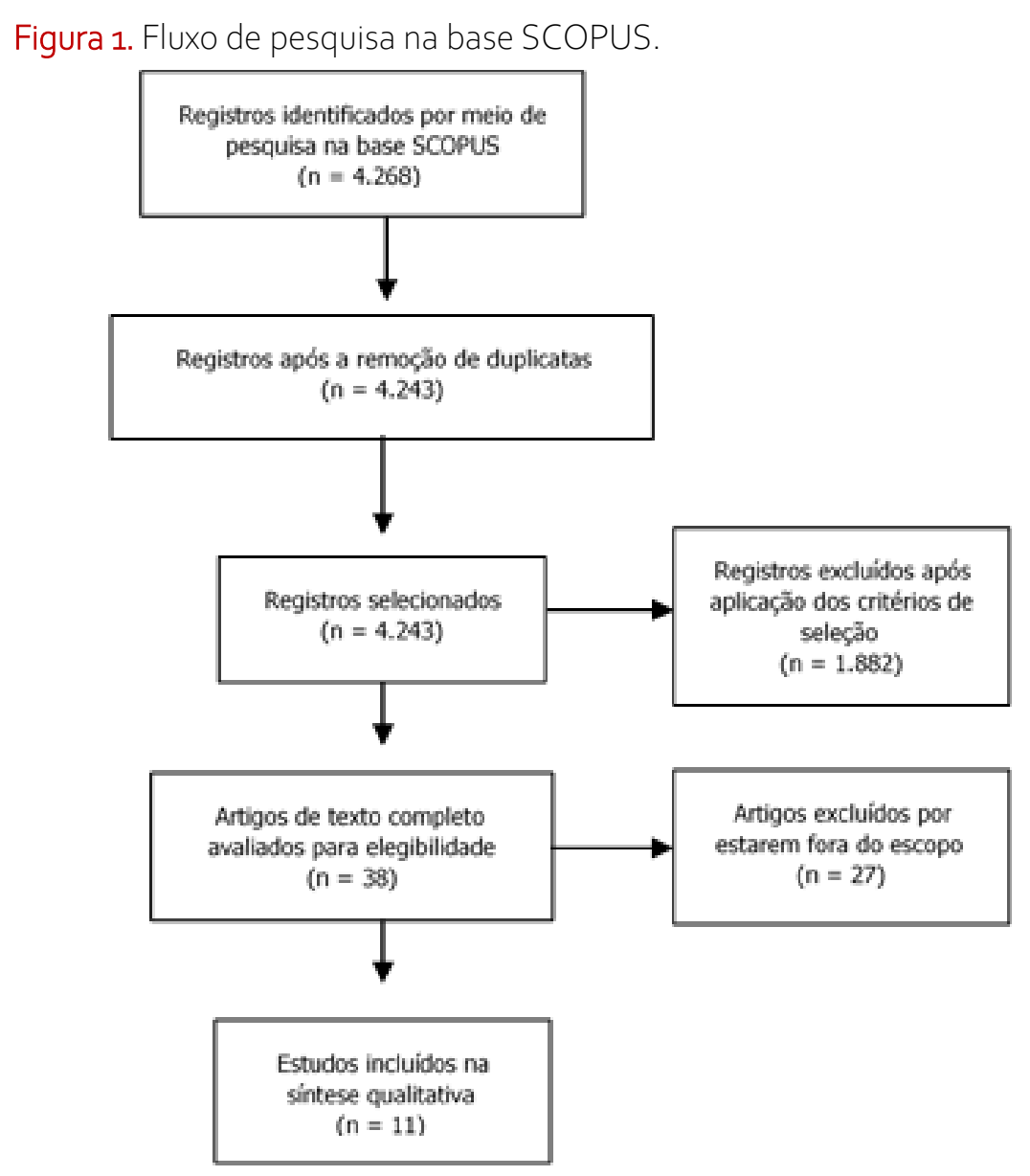

Fonte: dados da pesquisa, 2020

O quadro 1, disposto a seguir, apresenta uma síntese das características dos 11 estudos incluídos nesta revisão. Observa-se que o número de estudos empíricos relacionados às barreiras à informação em saúde nas mídias sociais é crescente entre os anos 2015 (1/11) e 2019 (5/11). Esta tendência indica o crescente reconhecimento dos pesquisadores da necessidade de entendimento do uso das mídias sociais para fins de obtenção de informação sobre saúde (BIXTER et al., 2019), considerando o cenário atual de proliferação das plataformas de mídia social. De notar que, embora não haja estudos incluídos dentro do escopo referente ao período de janeiro a março de 2020 (0/11) (que marca o recorte temporal da coleta de dados), há a possibilidade de publicações no ano de 2020 com outras/novas terminologias e perspectivas.

\begin{tabular}{|l|l|}
\hline \multicolumn{1}{|c|}{ Quadro 1. Síntese das características gerais dos estudos incluídos. } \\
\begin{tabular}{|l|l|}
\hline \multicolumn{1}{|c|}{ OCORRÊNCIA } \\
\hline Ano de Publicação & $2020(0 / 11) ; 2019(5 / 11) ; 2018(2 / 11) ; 2017(1 / 11) ; 2016(2 / 11) ;$ e $2015(1 / 11)$. \\
\hline País do primeiro autor & $\begin{array}{l}\text { EUA (3/11); Reino Unido (3/11); Canadá (1/11); Alemanha (1/11); Irã (1/11); } \\
\text { Paquistão (1/11); e Arábia Saudita (1/11). }\end{array}$ \\
\hline
\end{tabular}
\end{tabular}




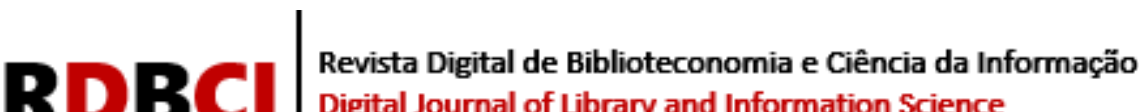 \\ Digital Journal of Library and Information Science}

\begin{tabular}{|l|l|}
\hline Área de conhecimento & $\begin{array}{l}\text { Medicina (7/11); Ciências Sociais (2/11); Ciência da Computação (1/11); e } \\
\text { Multidisciplinar (1/11). }\end{array}$ \\
\hline Tipo de estudos & Artigos (10/11) e Anais de Conferências (1/11). \\
\hline Abordagem metodológica & Qualitativa (5/11); quantitativa (3/11); e quali-quanti (3/11). \\
\hline Tema do objetivo do estudo & $\begin{array}{l}\text { Acesso e uso de informações sobre saúde na internet (2/11); compartilhamento } \\
\text { de informações sobre saúde on-line (2/11); papel da internet na autogestão da } \\
\text { saúde }(1 / 11) ; \text { envolvimento on-line do público de serviços de saúde (1/11); uso das } \\
\text { mídias sociais para fins de saúde (3/11); competência de informação sobre saúde } \\
\text { relacionada às mídias (1/11); e comportamento de busca de informação sobre } \\
\text { saúde (1/11). }\end{array}$ \\
\hline
\end{tabular}

Fonte: dados da pesquisa, 2020.

Os 11 estudos incluídos são originários de 7 países, distribuídos em 3 continentes: América - Estados Unidos da América (3/11) e Canadá (1/11); Europa - Reino Unido (3/11) e Alemanha (1/11); Ásia - Irã (1/11), Paquistão (1/11) e Arábia Saudita (1/11). Tal distribuição demonstra uma realidade comum nas sociedades globais: a presença das mídias sociais nas práticas cotidianas dos sujeitos na busca por informação sobre saúde. Além disso, sugere que os problemas relacionados à informação em saúde nas mídias sociais afetam países desenvolvidos e em desenvolvimento. Destaca-se a tendência crescente nos últimos anos de estudos nos países em desenvolvimento da Ásia: 2019 (Paquistão; Arábia Saudita) e 2018 (Irã).

A área da saúde apresenta o maior número de estudos - Medicina (7/11). No entanto, o aglomerado de estudos provenientes das outras áreas do conhecimento - Ciências Sociais (2/11), Ciência da Computação (1/11), Multidisciplinar (1/11) - constitui uma parcela significativa (36\%) que indica o caráter interdisciplinar do objeto desta revisão. Implica dizer que o objeto investigado integra diferentes interesses e perspectivas teórico-metodológicas relacionadas ao eixo da comunicação, informação, saúde e computação.

Os estudos incluídos são de língua inglesa, tipificados como artigos (10/11) e anais de conferências (1/11). Todos são decorrentes de pesquisas empíricas - com usuários leigos de informação sobre saúde - constituídas por abordagens metodológicas qualitativas (5/11), quantitativas (3/11) e quali-quanti (3/11). Os métodos empíricos utilizados foram: pesquisa online (3); survey (2); entrevistas semiestruturadas (2); grupos focais (2); análise de conteúdo (1); entrevistas emparelhadas com atividades online (1); e entrevistas em profundidade (1).

Os objetivos desses estudos abordam a utilização de informação sobre saúde em quatro perspectivas: a primeira em torno do ambiente geral da internet (6/11); a segunda vinculada diretamente às mídias sociais (3/11); a terceira abrangendo as mídias online e off-line (1/11); e a quarta sem fazer menção a qualquer tipo de mídia (1/11). Destaca-se que alguns objetivos não abordam o termo mídia social em seus enunciados. Contudo, todos os estudos abordam ou tangenciam as plataformas de mídia social na metodologia e/ou resultados. Além disso, apresentam resultados acerca das barreiras - dificuldades, riscos, desafios - relacionadas à informação sobre saúde nas mídias sociais, considerando as perspectivas de usuários leigos.

Os contextos de saúde investigados são diversos: saúde sexual dos adolescentes ou jovens adultos (2/11); pacientes de saúde em geral (2/11); pacientes diabéticos (1/11); pessoas diagnosticadas com depressão e ansiedade (1/11); adolescentes suscetíveis à comportamentos de alto risco (1/11); idosos que manifestam sentimentos de angústia (1/11); mulheres Lésbicas Bissexuais e Queers (LBQ) que tentam engravidar (1/11); participantes de intervenções em saúde sexual (1/11); e mulheres em busca de alimentação saudável (1/11). Alguns contextos 


\section{RDBC| \\ Digital Journal of Library and Information Science}

não apresentam motivações quanto ao uso para fins de informação sobre saúde (Quadro 2).

Quadro 2. Contextos, motivações e mídias sociais.

\begin{tabular}{|c|c|c|c|}
\hline ESTUDO & CONTEXTO & MOTIVAÇÕES & MIDIA SOCIAL \\
\hline $\begin{array}{l}\text { Patterson et } \\
\text { al. (2019) }\end{array}$ & $\begin{array}{l}\text { Jovens que acessam } \\
\text { informações sobre } \\
\text { saúde sexual online }\end{array}$ & $\begin{array}{l}\text { Embora céticos quanto ao uso das mídias } \\
\text { sociais no contexto da saúde sexual, têm } \\
\text { interesse em suporte on-line } \\
\text { particularizado quanto ao fornecimento de } \\
\text { conselhos em um ambiente confidencial. }\end{array}$ & $\begin{array}{l}\text { Não há } \\
\text { especificação }\end{array}$ \\
\hline Liao (2019) & $\begin{array}{l}\text { Pacientes de saúde em } \\
\text { geral dos EUA }\end{array}$ & $\begin{array}{l}\text { Facilitar o apoio social, combater o estigma, } \\
\text { estabelecer a auto-responsabildiade e } \\
\text { gerenciar as impressões são motivações } \\
\text { para o compartilhamento de informações } \\
\text { pessoais sobre saúde on-line. }\end{array}$ & $\begin{array}{l}\text { Não há } \\
\text { especificação }\end{array}$ \\
\hline $\begin{array}{l}\text { Nisar e Shafiq } \\
\qquad(2019)\end{array}$ & $\begin{array}{l}\text { Pacientes de saúde em } \\
\text { geral do Paquistão }\end{array}$ & $\begin{array}{l}\text { Aprender competências que ajudam a } \\
\text { gerenciar a saúde; observar o que outros } \\
\text { pacientes dizem; fornecer feedbacks sobre } \\
\text { serviços de saúde; obter informações sobre } \\
\text { especialistas/médicos; ter acesso a } \\
\text { especialistas e sites informativos; } \\
\text { compartilhar experiências; encontrar } \\
\text { recomendações e opiniões sobre saúde; } \\
\text { obter apoio moral de pacientes e médicos. }\end{array}$ & $\begin{array}{l}\text { Facebook; Youtube; } \\
\text { Google Plus. }\end{array}$ \\
\hline $\begin{array}{l}\text { Alzahrani e } \\
\text { Alanzi (2019) }\end{array}$ & $\begin{array}{l}\text { Pessoas diagnosticadas } \\
\text { com Diabetes da Arábia } \\
\text { Saudita }\end{array}$ & $\begin{array}{l}\text { Buscar informações sobre diabetes; } \\
\text { comunicar-se com outras pessoas com } \\
\text { diabetes para obter ajuda, conselhos e } \\
\text { trocar experiências; encontrar informações } \\
\text { específicas sobre tratamento e cuidados da } \\
\text { diabete. }\end{array}$ & $\begin{array}{l}\text { WhatsApp; } \\
\text { Instagram; Twitter; } \\
\text { Snapchat; } \\
\text { Facebook; Skype; } \\
\text { Tango. }\end{array}$ \\
\hline $\begin{array}{l}\text { Bernard et al. } \\
\qquad(2019)\end{array}$ & $\begin{array}{l}\text { Pessoas diagnosticadas } \\
\text { com depressão e } \\
\text { ansiedade na Alemanha }\end{array}$ & $\begin{array}{l}\text { Não há motivações específicas para o uso } \\
\text { da web de modo geral para fins de } \\
\text { informação. }\end{array}$ & $\begin{array}{l}\text { Não há } \\
\text { especificação }\end{array}$ \\
\hline $\begin{array}{l}\text { Moult et al. } \\
\qquad(2018)\end{array}$ & $\begin{array}{l}\text { Idosos que se } \\
\text { manifestam sentimento } \\
\text { de angústia no Reino } \\
\text { Unido }\end{array}$ & $\begin{array}{l}\text { Não há motivações para o uso de mídias } \\
\text { sociais. Ouvir relatos de amigos sobre as } \\
\text { mídias sociais é o motivo pelo qual os } \\
\text { participantes associam a elas conteúdo on- } \\
\text { line negativo. }\end{array}$ & $\begin{array}{l}\text { Não há } \\
\text { especificação }\end{array}$ \\
\hline $\begin{array}{l}\text { Esmaeilzadeh } \\
\text { et al. (2018) }\end{array}$ & $\begin{array}{l}\text { Adolescentes } \\
\text { suscetíveis a } \\
\text { comportamentos de } \\
\text { alto risco do Irã }\end{array}$ & $\begin{array}{l}\text { Buscar informações preliminares para } \\
\text { atender as necessidades sobre inatividade, } \\
\text { comportamentos sexuais de alto risco, e } \\
\text { incidentes ou lesões. }\end{array}$ & $\begin{array}{l}\text { Não há } \\
\text { especificação }\end{array}$ \\
\hline $\begin{array}{l}\text { Ruppel et al. } \\
\quad(2017)\end{array}$ & $\begin{array}{l}\text { Mulheres Lésbicas, } \\
\text { Bissexuais e Queers } \\
\text { (LBQ) que tentam } \\
\text { engravidar nos EUA }\end{array}$ & $\begin{array}{l}\text { Buscar ou fornecer aconselhamento } \\
\text { médico relacionado ao processo de } \\
\text { inseminação artificial, gravidez e parto. }\end{array}$ & Facebook \\
\hline $\begin{array}{l}\text { Glik et al. } \\
\text { (2016) }\end{array}$ & $\begin{array}{l}\text { Adolescentes e jovens } \\
\text { adultos que buscam } \\
\text { informações sobre } \\
\text { saúde sexual no } \\
\text { Senegal }\end{array}$ & $\begin{array}{l}\text { As mídias podem ser um meio pelo qual se } \\
\text { busca informações sobre saúde sexual } \\
\text { evitando embaraços e vergonha ao fazê-la } \\
\text { com a família. Além disso, há a motivação } \\
\text { de estar em contato com outros } \\
\text { senegaleses. }\end{array}$ & Facebook \\
\hline $\begin{array}{l}\text { Witzel et al. } \\
\qquad(2016)\end{array}$ & $\begin{array}{l}\text { Homens Gays ou } \\
\text { Bissexuais participantes } \\
\text { de intervenções de }\end{array}$ & $\begin{array}{l}\text { Compartilhar informações sobre a } \\
\text { prevenção do HIV a fim de conscientizar }\end{array}$ & Facebook \\
\hline
\end{tabular}




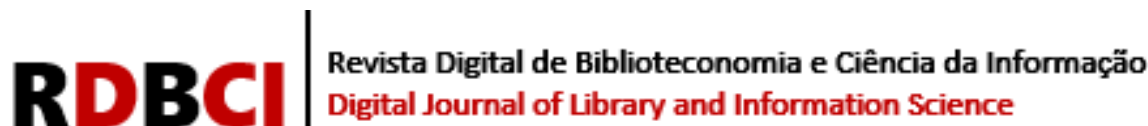

\begin{tabular}{|c|l|l|l|}
\hline & $\begin{array}{l}\text { saúde sexual no Reino } \\
\text { Unido }\end{array}$ & $\begin{array}{l}\text { outras pessoas; Acessar informações sobre } \\
\text { medicamentos. }\end{array}$ & \\
\hline $\begin{array}{c}\text { Bissonnette- } \\
\begin{array}{c}\text { Maheux et al. } \\
\text { (2015) }\end{array}\end{array}$ & $\begin{array}{l}\text { Mulheres que buscam } \\
\text { informações sobre } \\
\text { alimentos saudáveis no } \\
\text { Canadá }\end{array}$ & $\begin{array}{l}\text { Meio de informação sobre novos alimentos, } \\
\text { tendências, receitas saudáveis e } \\
\text { conhecimento sobre nutrição em geral. }\end{array}$ & Blogs \\
\hline
\end{tabular}

Fonte: dados da pesquisa, 2020.

Os estudos apresentam 21 barreiras (Quadro 3). Nesta revisão, essas barreiras são agrupadas em uma malha de meta-barreiras composta por cinco categorias - diaspóricas (9), desinformação (2), interação (5), letramento (3) e emocionais (2). Considerando que a abordagem desta revisão é a das práticas informacionais (LLOYD, 2010) em transição (LLOYD, 2014), buscou-se apresentar a malha de barreiras - a fim de interconectar as barreiras - de modo articulado com os contextos de saúde dos sujeitos, as motivações que os fazem considerar as mídias sociais como fonte de informação sobre saúde, e as mídias sociais utilizadas.

Quadro 3. Barreiras vinculadas às mídias sociais.

\begin{tabular}{|c|c|c|}
\hline META-BARREIRAS & BARREIRAS & ESTUDOS \\
\hline \multirow{9}{*}{ 1. Diaspóricas } & $\begin{array}{l}\text { 1) Tensões culturais entre as práticas liberais de } \\
\text { mídia social e a tradição; }\end{array}$ & Glik et al. (2016) \\
\hline & 2) Falta de confiança nas informações e fontes; & $\begin{array}{l}\text { Nisar e Shafiq (2019); Moult et al. } \\
\text { (2018); Glik et al. (2016) }\end{array}$ \\
\hline & $\begin{array}{l}\text { 3) Conflitos de interesse quanto a publicidade e } \\
\text { provimento de informações. }\end{array}$ & Bissonnette-Maheux et al. (2015) \\
\hline & $\begin{array}{l}\text { 4) Excesso de informações disponíveis e } \\
\text { notificações; }\end{array}$ & $\begin{array}{c}\text { Patterson et al. (2019); } \\
\text { Bissonnette-Maheux et al. (2015) }\end{array}$ \\
\hline & 5) Informações e fontes desconhecidas; & Ruppel et al. (2017) \\
\hline & $\begin{array}{l}\text { 6) Disparidade entre as informações disponíveis e } \\
\text { necessárias; }\end{array}$ & Ruppel et al. (2017) \\
\hline & 7) Informações imprecisas; & $\begin{array}{l}\text { Alzahrani e Alanzi (2019); Ruppel } \\
\text { et al. (2017) }\end{array}$ \\
\hline & 8) Informações insuficientes ou limitadas; & $\begin{array}{l}\text { Nisar e Shafiq (2019); Ruppel et al. } \\
\text { (2017) }\end{array}$ \\
\hline & 9) Ausência de informações novas; & Bissonnette-Maheux et al. (2015) \\
\hline \multirow[t]{2}{*}{ 2. Desinformação } & 10) Informações incorretas ou equivocadas; & $\begin{array}{l}\text { Nisar e Shafiq, (2019); Alzahrani e } \\
\text { Alanzi (2019); Ruppel et al. (2017) }\end{array}$ \\
\hline & 11) Ter ciência da propagação da desinformação; & Nisar e Shafiq (2019) \\
\hline \multirow[b]{2}{*}{ 3. Letramento } & 12) Conhecimento limitado sobre as fontes on-line; & Patterson et al. (2019) \\
\hline & $\begin{array}{l}\text { 13) Dificuldade de encontrar informações } \\
\text { localmente relevantes ou apropriadas; }\end{array}$ & $\begin{array}{l}\text { Patterson et al. (2019); } \\
\text { Esmaeilzadeh et al. (2018) }\end{array}$ \\
\hline
\end{tabular}




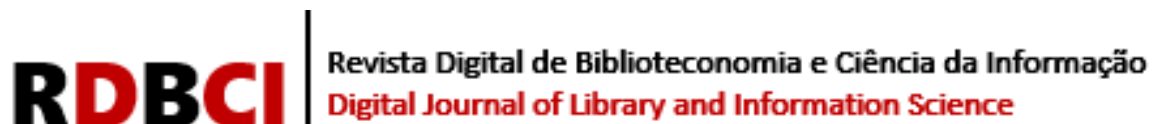

\begin{tabular}{|c|c|c|}
\hline & $\begin{array}{l}\text { 14) Determinar a qualidade das informações } \\
\text { encontradas; }\end{array}$ & Esmaeilzadeh et al. (2018) \\
\hline \multirow{5}{*}{ 4. Interação } & $\begin{array}{l}\text { 15) Superexposição - alvo de elogios ou } \\
\text { reclamações, comunicação argumentativa; }\end{array}$ & $\begin{array}{c}\text { Glik et al. (2016); Nisar e Shafiq } \\
\text { (2019); Moult et al. (2018); Witzel } \\
\text { et al. (2016) }\end{array}$ \\
\hline & 16) Preocupações com a privacidade & $\begin{array}{c}\text { Patterson et al. (2019); Liao } \\
\text { (2019); Nisar e Shafiq (2019); } \\
\text { Alzahrani e Alanzi (2019); Bernard } \\
\text { et al. (2019); Esmaeilzadeh et al. } \\
\text { (2018); Glik et al. (2016); Witzel et } \\
\text { al. (2016) }\end{array}$ \\
\hline & 17) Comparação social que gera afetos negativos; & Bernard et al. (2019) \\
\hline & 18) Contatos ambivalentes; & Bernard et al. (2019) \\
\hline & $\begin{array}{l}\text { 19) Conteúdo inesperado e respostas ou } \\
\text { comentários não solicitados; }\end{array}$ & $\begin{array}{l}\text { Bernard et al. (2019); Ruppel et al. } \\
\text { (2017) }\end{array}$ \\
\hline \multirow{2}{*}{ 5. Emocionais } & $\begin{array}{l}\text { 20) Falta de apoio para recuperação de erros e } \\
\text { superação de dificuldades emocionais; }\end{array}$ & Bernard et al. (2019) \\
\hline & $\begin{array}{l}\text { 21) Conteúdos que lembram experiências } \\
\text { perturbadoras ou afetos negativos; }\end{array}$ & Bernard et al. (2019) \\
\hline
\end{tabular}

Fonte: dados da pesquisa, 2020.

\subsection{Barreiras diaspóricas}

As barreiras diaspóricas correspondem às experiências instáveis dos sujeitos com as fontes de informação desconhecidas e dispersas frente a transição do contexto (BRASILEIRO, 2019). No ambiente digital, a experiência diaspórica do usuário envolve o desafio de conciliar as suas práticas habituais e os exercícios instáveis de ambiguidade e cooperação demandados pela tradução da informação na internet (GONZÁLEZ DE GÓMEZ, 2004). Nesta revisão da literatura, esse desafio é abordado como tensão entre as práticas liberais vinculadas às mídias sociais e os valores culturais tradicionais (GLIK et al., 2016). Trata-se de uma barreira que emerge a partir da adoção do Facebook por adolescentes do Senegal como estratégia de informação frente aos valores culturais locais de informação sobre o contexto da saúde sexual (GLIK et al., 2016).

Outra barreira relacionada a esse contexto da saúde sexual é a falta de confiança nas informações (GLIK et al., 2016), a qual também emerge nos contextos de saúde de idosos que sofrem de angústia (MOULT et al., 2018) e de pacientes em geral que usam as mídias sociais - Facebook, Youtube, Wikipedia, Google Plus - como ferramenta para buscar e compartilhar informações sobre saúde (NISAR; SHAFIQ, 2019). No contexto dos idosos, entretanto, a desconfiança está previamente associada às percepções negativas acerca das mídias sociais, que, somadas à vulnerabilidade emocional vivenciada, desmotivam o uso dessas mídias como um suporte social/informacional relacionado à autogestão da angústia (MOULT et al., 2018).

Os conflitos de interesse quanto ao acesso à promoção de produtos e publicidades enquanto se utiliza blogs de informação sobre nutrição são considerados barreiras por mulheres (BISSONNETTE-MAHEUX et al., 2015) que não apresentam uma doença crônica, mas 


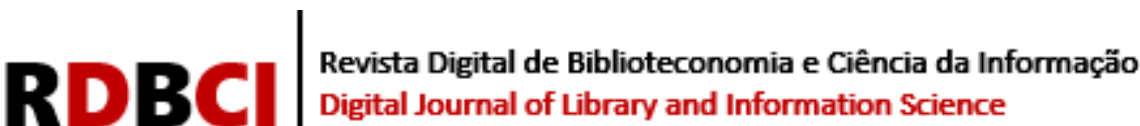

buscam conhecimento sobre alimentos saudáveis e tendências de nutrição para fins de cuidados dietéticos. Nesse contexto, o excesso de notificações sobre novas postagens e a ausência de informações novas (BISSONNETTE-MAHEUX et al., 2015) também são considerados dificuldades para o uso de informação em blogs. O excesso de conteúdos também é percebido como barreira por jovens adultos do Reino Unido que buscam informações sobre saúde sexual (PATTERSON et al., 2019). A diferença é que, no contexto de saúde sexual, o excesso desmotiva as práticas de busca ativa da informação (MCKENZIE, 2003), ao passo que, no contexto nutricional, gera desconforto durante a prática de evitar a informação (BRASHERS et al., 2002).

No contexto de mulheres Lésbicas, Bissexuais e Queers (LBQ) dos EUA que tentam engravidar e buscam informações em grupos do Facebook, sobre inseminação artificial e concepção, as barreiras diaspóricas abrangem: informações desconhecidas e fontes não fornecidas; disparidade entre informações necessárias e disponíveis; informações imprecisas; informações limitadas (RUPPEL et al., 2017). As informações imprecisas também são percebidas como barreira por diabéticos da Arábia Saudita que usam mídias sociais WhatsApp, Instagram, Twitter, Facebook, Tango - para buscar e compartilhar informações sobre diabetes (ALZAHRANI; ALANZI, 2019). Essa mesma barreira também é percebida por pacientes de saúde em geral do Paquistão que usam as mídias sociais - Facebook, Youtube, Google Plus - para buscar e compartilhar informações sobre saúde (NISAR; SHAFIQ, 2019).

Todas estas barreiras apresentadas (RUPPEL et al., 2017; ALZAHRANI, ALANZI, 2019; NISAR, SHAFIQ, 2019) vão ao encontro da concepção de desinformação como informação imprecisa, distorcida, incerta, vaga ou ambígua (KARLOVA; FISHER, 2013). Sendo assim, é possível nomeá-las também como barreiras de desinformação. Contudo, adotase o termo "barreiras diaspóricas” ao invés de "barreiras de desinformação" a fim de abarcar e demarcar as tensões transitórias que particularizam os diferentes contextos: de um lado, as mulheres LBQ dos EUA que estão à margem da normatividade da maternidade e precisam conciliar suas práticas e necessidades com os padrões de informação instituídos e reproduzidos no ambiente das mídias sociais (RUPPEL et al., 2017); do outro, as populações dos países em desenvolvimento da Ásia que precisam conciliar suas práticas socioculturais locais de saúde com as lógicas liberais da mídia social (ALZAHRANI, ALANZI, 2019; NISAR, SHAFIQ, 2019).

Além disso, o termo “desinformação” é constantemente utilizado para se referir às informações erradas (OXFORD, 2017), quer sejam deliberadas ou acidentais (STAHL, 2006). O termo "barreiras diaspóricas", por outro lado, possibilita vincular as múltiplas dificuldades de informação percebidas pelos sujeitos - no uso das mídias sociais - ao contexto de transição particular vivenciado. Nesta revisão, esse tipo de barreiras sugere um impacto maior às práticas nas mídias sociais em contextos de saúde caracterizados como significativos e pessoais (CLEMENS; CUSHING, 2010) - saúde em geral (NISAR; SHAFIQ, 2019), saúde sexual (PATTERSON et al., 2019) (GLIK et al., 2016), idosos (MOULT et al., 2018), diabetes (ALZAHRANI; ALANZI, 2019), maternidade (RUPPEL et al., 2017) - comparados aos contextos de saúde vinculados às rotinas estáveis, a exemplo do bem-estar e de práticas dietéticas (BISSONNETTE-MAHEUX et al., 2015).

\subsection{Barreiras de desinformação}

O termo "barreiras de desinformação" é adotado para se referir especificamente às experiências instáveis com as informações que não sustentam a verdade (KARLOVA; LEE, 2011), quer seja as informações falsas, manipuladas deliberadamente (STAHL, 2006), ou as informações percebidas como falsas no contato com as fontes (KARLOVA; LEE, 2011). Nesta 


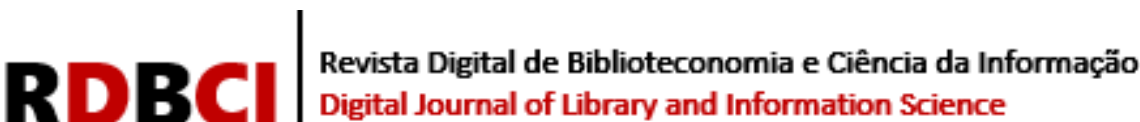

revisão, informações incorretas ou equivocadas foram percebidas como barreiras nos seguintes contextos: mulheres LBQ dos EUA que buscam informações sobre gravidez (RUPPEL et al., 2017); pacientes do Paquistão que buscam e/ou compartilham informações acerca da saúde (NISAR; SHAFIQ, 2019); diabéticos da Arábia Saudita que buscam e compartilham informações sobre diabetes (ALZAHRANI; ALANZI, 2019).

No contexto das mulheres (RUPPEL et al., 2017), as mídias sociais foram utilizadas de modo direcionado às questões específicas, relacionadas à inseminação artificial e concepção, isto é, nas modalidades de busca e exploração ativa da informação (MCKENZIE, 2003). Isso indica que a percepção das informações equivocadas pode estar relacionada a uma consciência prévia acerca das verdades normativas ou médicas do contexto. Já nos contextos dos pacientes de saúde em geral do Paquistão (NISAR; SHAFIQ, 2019) e dos diabéticos da Arábia Saudita (ALZAHRANI; ALANZI, 2019), a utilização das mídias sociais está direcionada às questões gerais dos cuidados com a saúde e a diabetes, podendo variar entre diferentes modos de busca da informação, como a exploração ativa, o monitoramento não dirigido ou por procuração (MCKENZIE, 2003). Isso indica que a percepção de informações incorretas, nesses dois contextos, pode estar ligada ao alto fluxo de informações e ao letramento digital limitado.

No contexto dos pacientes de saúde em geral do Paquistão, essa relação com o fluxo de informações e o letramento digital limitado fica mais evidente quando percebem a propagação da desinformação como outra barreira para o uso das mídias sociais (NISAR; SHAFIQ, 2019). Isso demonstra que existe uma consciência prévia sobre a possibilidade de não haver competências críticas para julgar e avaliar o que é certo ou errado, diante das informações encontradas nas mídias sociais, e de tomar decisões equivocadas sobre saúde. Nesse sentido, percebe-se que a barreira de desinformação se inter-relaciona com outra barreira determinante às práticas de autogestão das informações sobre saúde nas mídias sociais: a de letramento.

\subsection{Barreiras de letramento}

As barreiras de letramento se referem às restrições de recursos ou disposições individuais e coletivas para determinar a extensão das fontes, acessar a informação de forma efetiva e eficiente e avaliar criticamente as informações e suas fontes (BRASILEIRO, 2019). As barreiras de letramento enfrentadas pelos jovens do Reino Unido, no acesso a informações e apoio à saúde sexual on-line, se restringem à ausência de orientações sobre as fontes específicas e a dificuldade de encontrar informações localmente relevantes (PATTERSON et al., 2019). Enquanto a ausência de orientações sobre as fontes indica tanto o desconhecimento do cenário de informação sobre saúde (LLOYD, 2014) quanto a necessidade de construção do suporte informacional online (BRASILEIRO, 2019), a dificuldade de encontrar informações localmente relevantes reforça o desconhecimento do cenário de informação, mas, sobretudo, problematiza o encontro com as informações que ora se apresentam como redundantes.

O desconhecimento do cenário de informação on-line sobre saúde sexual desperta incertezas sobre as informações acessadas nas mídias sociais (BRASILEIRO, 2019), bem como insegurança para o engajamento com as fontes e a tomada de decisões. $\mathrm{O}$ encontro com informações redundantes significa que, embora plurais, as mídias sociais tendem a reproduzir um valor de informação comum (GONZÁLEZ DE GÓMEZ, 2012) sobre saúde sexual. O desconhecimento deste cenário online, portanto, dificulta a transição dos padrões de informação e a conexão com informações relevantes adequadas às realidades locais. Neste caso, o suporte informacional online construído de forma situacional e negociada permite conhecer de modo significativo a extensão das fontes e encontrar informações relevantes (BRASILEIRO, 2019).

Encontrar informações apropriadas também é um problema no contexto de saúde de 


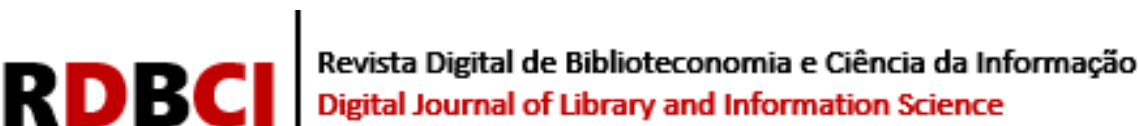

adolescentes suscetíveis a comportamentos de alto risco no Irã (relacionados ao tabagismo, à inatividade física, ao consumo de álcool, ao comportamento sexual de risco, entre outros). Outra dificuldade considerada neste contexto é determinar a qualidade das informações encontradas durante as buscas preliminares (ESMAEILZADEH et al., 2018). Tal barreira pode ser vinculada às incertezas decorrentes do desconhecimento do cenário de informação sobre saúde (LLOYD, 2014), que fragmentam o valor de informação e podem impedir a atribuição de qualidade.

Todas as barreiras de letramento identificadas são inter-relacionadas com as barreiras diaspóricas, uma vez que emergem das situações instáveis dos sujeitos em uma nova ambiência informacional sobre saúde nas mídias sociais, a qual, por sua vez, demanda novas competências. Isso indica que o letramento informacional online não é suscetível de ser construído plenamente pelas estruturas formais prévias (HICKS; LLOYD, 2016), mas, sobretudo, necessita ser construído situacionalmente em contexto e em colaboração (LLOYD, 2014). Tal colaboração, por sua vez, apresenta desafios e dilemas à autogestão de informações sobre saúde à medida que exige negociação entre os múltiplos objetivos conflitantes (BRASHERS et al., 2002). Nesse sentido, as barreiras de letramento se inter-relacionam com as barreiras de interação.

\subsection{Barreiras de interação}

As barreiras de interação correspondem aos dilemas e desafios intersubjetivos e situacionais que envolvem a articulação entre as práticas de autogestão de informações (BRASHERS et al., 2002) e as dinâmicas do trabalho de face (GOFFMAN, 1967). Nesta revisão, as barreiras de interação apontadas pelos estudos foram agrupadas em duas temáticas: (a) a preocupação com a perda da privacidade e da reputação durante as práticas on-line de busca e compartilhamento de informações (PATTERSON et al., 2019; LIAO, 2019; NISAR; SHAFIQ, 2019; ALZAHRANI; ALANZI, 2019; BERNARD et al., 2019; ESMAEILZADEH et al., 2018; GLIK et al., 2016; WITZEL et al., 2016); (b) o desconforto com os atos online de ameaça à face durante as práticas de evite (NISAR; SHAFIQ, 2019; BERNARD et al., 2019; RUPPEL et al., 2017). Ambas temáticas se configuram como barreiras à autogestão das informações sobre saúde nas mídias sociais.

A preocupação com a perda da privacidade e reputação (a) consiste numa barreira presente em grande parte dos estudos incluídos (9/11). Parte desses estudos revela a preocupação dos usuários com a privacidade de um modo geral: os usuários de mídias sociais dos EUA que compartilham informações pessoais e de saúde (LIAO, 2019); os pacientes de saúde em geral do Paquistão que buscam ou compartilham informações sobre saúde nas mídias sociais (NISAR; SHAFIQ, 2019); as pessoas diagnosticadas com depressão e transtornos de ansiedade da Alemanha que utilizam a internet (BERNARD et al., 2019); e os adolescentes do Senegal que buscam informações nas mídias sociais sobre saúde (GLIK et al., 2016).

Os jovens adultos do Reino Unido que buscam informações sobre saúde sexual (PATTERSON et al., 2019) associam a preocupação com a perda da privacidade aos riscos de constrangimento (GOFFMAN, 1967): ser visto buscando informações sobre saúde sexual; deixar rastros nas mídias sociais sobre os conteúdos relacionados à saúde sexual; e medo de passar vergonha ou constrangimento (PATTERSON et al., 2019). Tais barreiras se relacionam às barreiras diaspóricas à medida que emergem dos conflitos transitórios entre a pouca experiência dos jovens e o dinâmico ambiente on-line de informação sobre saúde sexual (PATTERSON et al., 2019). A preocupação com a perda da privacidade no contexto de pacientes diabéticos da Arábia Saudita (ALZAHRANI; ALANZI, 2019) e no contexto dos participantes de intervenções em saúde no Reino Unido (WITZEL et al., 2016) está ligada às questões de segurança de dados pessoais. Estes usuários de mídias sociais do Reino Unido 


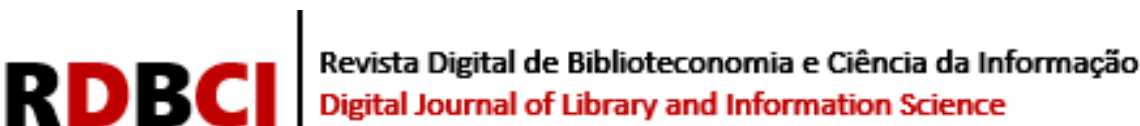

(WITZEL et al., 2016), juntamente com os estudantes adolescentes do Irã (ESMAEILZADEH et al., 2018), também associam a perda de privacidade à reputação ${ }^{1}$ - especificamente aos riscos de divulgação de informações pessoais.

Essas barreiras mostram o trabalho de face (GOFFMAN, 1967) como um objetivo conflitante frente aos objetivos informacionais acerca da saúde nas mídias sociais (BRASILEIRO, 2019). Do mesmo modo, a necessidade de gestão dos atos online de ameaça à face (b) também é conflitante com as práticas de evite da informação e da interação. A esse respeito, os pacientes do Paquistão apontam como barreira o fato de a superexposição nas mídias sociais os tornarem alvo de elogios ou reclamações (NISAR; SHAFIQ, 2019). Para as pessoas diagnosticadas com depressão e ansiedade da Alemanha (BERNARD et al., 2019), essas barreiras estão associadas às dicas de comparação social e aos contatos ambivalentes. As pessoas desse contexto (BERNARD et al., 2019), assim como as mulheres LBQ dos EUA (RUPPEL et al., 2017), também associam tais barreiras às respostas ou comentários inesperados quando não são solicitados.

Todas essas barreiras de interação demonstram que as plataformas de mídia social, ao mesmo tempo em que podem promover a conexão com uma variedade de informações sobre saúde, podem oferecer ameaças à reputação e exigem práticas cautelosas (BRASILEIRO, 2019) envolvendo a preservação da face (GOFFMAN, 1967). Isso justifica o evite das práticas de busca e compartilhamento de informações pessoais sobre saúde, a fim de manter a reputação e o conforto - uma atitude baseada nos sentimentos morais compartilhados (COLLINS, 2004), que se inter-relaciona às barreiras emocionais individuais à medida que impede o engajamento com as fontes (pessoas) nas mídias sociais, como acontece, por exemplo, com o medo de passar vergonha (PATTERSON et al., 2019).

\subsection{Barreiras emocionais}

As barreiras emocionais são relacionadas aos sentimentos de ansiedade, medo, desanimo, entre outros, que interferem nas capacidades individuais de tomar decisões, estabelecer consenso, selecionar e se apropriar de fontes de informação relevantes, bem como na disposição para enfrentar uma situação adversa (BRASILEIRO, 2019). Nesta revisão, tais barreiras são percebidas no contexto das pessoas diagnosticadas com depressão e transtornos de ansiedade da Alemanha que utilizam a internet no cotidiano (BERNARD et al., 2019). Nesse contexto de saúde, duas circunstâncias foram apontadas: (a) falta de apoio para a recuperação dos erros e a superação de dificuldades emocionais; (b) conteúdos que lembram experiências perturbadoras ou afetos negativos (BERNARD et al., 2019).

A primeira (a) revela que o estado de vulnerabilidade emocional experienciado em contextos de vida significativos e pessoais (CLEMENS; CUSHING, 2010) demanda um suporte informacional e emocional para o desenvolvimento da resiliência informacional (LLOYD, 2014). Entretanto, as pessoas se deparam com dificuldades para a construção desse suporte nas mídias sociais tendo em vista os desafios e dilemas quanto à negociação dos múltiplos objetivos concorrentes (BRASHERS et al., 2002). A segunda (b) indica que o estado de vulnerabilidade emocional influencia a percepção de conteúdos associados às experiências de baixa energia emocional (COLLINS, 2004) no âmbito das mídias sociais, os quais, por sua vez, dificultam o enfrentamento das barreiras e a construção da resiliência informacional.

As barreiras emocionais podem, portanto, determinar a não motivação para o uso das

\footnotetext{
${ }^{1}$ Os participantes de intervenções de saúde sexual também associam a preocupação com a perda da privacidade ao risco de assumir uma identidade estigmatizada, a qual pode implicar no envolvimento com as intervenções de saúde sexual nas mídias sociais (Witzel et al., 2016)
} 


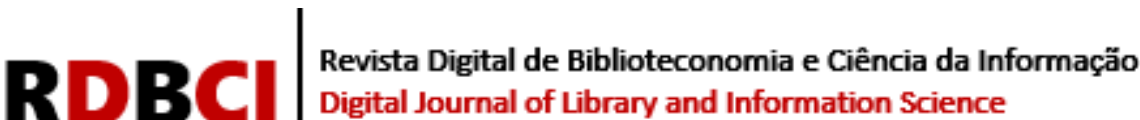

mídias sociais na busca por informações sobre saúde, mesmo quando outras barreiras situacionais ou contextuais relacionadas à informação não são evidentes, a exemplo das barreiras de letramento ou de desinformação. Isso indica que os estudos sobre E-Health precisam lançar mão das questões emocionais em sua agenda de investigação - envolvendo práticas, interações e comportamentos dos usuários - acerca dos usos das mídias sociais.

\section{DISCUSSÃO}

Os resultados encontrados demonstram que as barreiras à informação em saúde nas mídias sociais são múltiplas e variam conforme os contextos de saúde e as motivações situacionais que deles emergem. Algumas barreiras apresentadas são recorrentes e corroboram com os achados de estudos anteriores, a exemplo da preocupação com a privacidade e confiabilidade (ANTHEUNIS et al., 2013). Outras são apresentadas de modo original na perspectiva da transição, como as tensões e conflitos que compõem as barreiras diaspóricas.

Diante disso, apresentá-las de modo transversal sob a abordagem das práticas informacionais (LLOYD, 2010), numa perspectiva da transição de contextos de saúde (LLOYD, 2014) significativos e pessoais (CLEMENS; CUSHING, 2010), possibilita situar as dinâmicas dessas barreiras e seus impactos em todo o processo de autogerenciamento de informações sobre saúde. Nesta revisão, essa abordagem envolveu a articulação entre as barreiras, motivações, contextos e mídias sociais, o que permitiu a indicação da malha de (meta) barreiras inter-relacionadas: diaspóricas, desinformação, letramento, interação e emocionais.

Embora os estudos incluídos desvelem as múltiplas barreiras (Quadro III) percebidas nos diferentes contextos, constata-se que a abordagem baseada em práticas de informação não é central nesses estudos. Além disso, a investigação das barreiras vinculadas explicitamente às mídias sociais é central em apenas três estudos (LIAO, 2019; NISAR, SHAFIQ, 2019; ALZAHRANI, ALANZI, 2019). Tal constatação indica que a investigação sobre as barreiras à informação em saúde nas mídias sociais tende a ser secundária - como desdobramento dos estudos acerca dos comportamentos de uso da informação sobre saúde na internet - ou restrita às análises das dificuldades relacionadas a alguns dos aspectos materiais das mídias sociais.

O estudo das barreiras, por outro lado, quando articulado aos contextos, às motivações e às mídias sociais, se configura como uma alternativa para a compreensão das dinâmicas acerca dos cuidados de saúde envolvendo mídias sociais (ANTHEUNIS et al., 2013) na medida em que permite revelar outras questões subjetivas e situacionais complexas, como, por exemplo, os múltiplos significados que a informação pode assumir, os múltiplos objetivos informacionais e as múltiplas respostas que os sujeitos podem apresentar nas situações de interação (BRASHERS et al., 2002). Nesse sentido, a malha de barreiras inter-relacionadas pode se configurar como recurso analítico às questões complexas acerca da saúde nas mídias sociais.

Nos estudos incluídos, as barreiras são apresentadas sob a perspectiva dos aspectos sociotécnicos comuns à materialidade das mídias sociais, como, por exemplo, a disponibilidade pública, a possibilidade de alteração a qualquer momento, o público global, o imediatismo das informações, a facilidade de uso, a relevância contextual, a sobrecarga de informações e o excesso de spams (AGARWAL; YILIYASI, 2010). No entanto, a adoção dessa perspectiva, por si só, poderá não abarcar todas as barreiras que emergem do uso das mídias sociais no processo de transição do contexto de saúde, uma vez que deixa de lado barreiras que são inerentes ao próprio contexto de transição e, portanto, precedem as barreiras de cunho tecnológico. Contudo, ressalta-se que alguns dos estudos (PATTERSON et al., 2019; GLIK et al., 2016; RUPPEL et al., 2017; WITZEL et al., 2016) conseguem indicar uma integração entre essa perspectiva sociotécnica e os contextos de transição. 


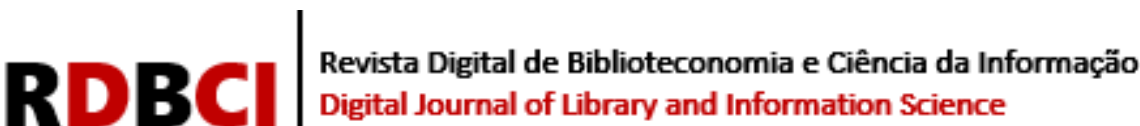

As motivações quanto ao uso das mídias sociais apresentadas em alguns estudos incluídos (NISAR; SHAFIQ, 2019; ALZAHRANI; ALANZI, 2019; ESMAEILZADEH et al., 2018; RUPPEL et al., 2017; GLIK et al., 2016; BISSONNETTE-MAHEUX et al., 2015) vão ao encontro das motivações apresentadas na literatura, a exemplo da necessidade de aumentar o conhecimento sobre a doença, expressar emoções, compartilhar experiências, obter aconselhamentos, encontrar respostas para perguntas específicas e fazer contato com médicos (ANTHEUNIS et al., 2013; DE MARTINO et al., 2017). Outras são apresentadas de modo original, como o combate ao estigma e a gestão de impressões (LIAO, 2019). Contudo, em geral, as motivações apresentadas não são relacionadas ao caráter situacional das práticas de autogestão de informações (BRASHERS et al., 2002), o que pode impedir a compreensão das barreiras situacionais do contexto. Além disso, alguns estudos (PATTERSON et al., 2019; BERNARD et al., 2019; MOULT et al., 2018; WITZEL et al., 2016) revelam que os sujeitos não apresentam motivações quanto ao uso das mídias sociais para buscar informações sobre saúde, devido às percepções negativas a elas associadas, a exemplo da falta de confiança e de credibilidade (SOUSA; ALMEIDA, 2016). Isso indica que as barreiras pré-existentes na dimensão das experiências dos usuários, somadas às tensões do contexto de transição, influenciam as motivações para o uso das mídias sociais na saúde. Sendo assim, devem ser consideradas pelas intervenções - baseadas em mídias digitais - de atores institucionais e de políticas públicas no sentido de otimizar as estratégias de comunicação pública em saúde.

Algumas limitações desta revisão da literatura precisam ser pontuadas. Embora os termos de pesquisa tenham sido pensados a fim de abarcar o objeto estudado, reconhece-se a possibilidade de não abarcarem a terminologia utilizada por outros estudos relacionados ao mesmo escopo. Isso porque o objeto das barreiras pode assumir múltiplas variações terminológicas no âmbito dos estudos da comunicação e informação em saúde, como, por exemplo: dificuldades, obstáculos, desafios, restrições, impedimentos, etc. Reconhece-se, também, que a utilização de uma única base de dados restringe a seleção de estudos relevantes. Embora esse entendimento seja explícito no modelo PRISMA, optou-se por uma única base de dados por questão de conveniência, considerando que o estudo não pretende se enquadrar como uma "revisão sistemática da literatura”, mas sim como uma "revisão exploratória” (escopo).

A malha de barreiras apresentada se baseou nas barreiras (dificuldades, restrições, impedimentos) percebidas pelos sujeitos empíricos dos estudos incluídos, de acordo com as evidências apontadas e relatadas. Desse modo, por ser constituída como meta-barreiras, essa malha pode apresentar limites quanto à representação da realidade empírica das barreiras descritas no Quadro III, uma vez que envolve a perspectiva dos pesquisadores quanto à articulação entre barreiras, motivos, contextos e mídias. Ademais, as barreiras podem se relacionar com outras meta-barreiras não incluídas nesta malha, mas que são presentes nas práticas de informação, como, por exemplo: as barreiras de rede, relacionadas aos limites das conexões fracas ou fortes nas mídias sociais, que podem determinar o alcance das informações (JOHNSON; CASE, 2012; BRASILEIRO, 2019); as barreiras tecnológicas, ligadas às dimensões da interface ${ }^{2}$ e da arquitetura da informação, que podem influenciar a confiança e credibilidade das informações em saúde (SOUSA; ALMEIDA, 2016; BRASILEIRO; FREIRE, 2012).

A partir desta revisão de literatura, portanto, a malha de barreiras apresentada com base nos resultados, embora limitada à determinadas categorias, permite compreender a fundo

\footnotetext{
2 Embora não tenham sido categorizadas como meta-barreiras, algumas barreiras tecnológicas podem ser visualizadas em alguns dos estudos incluídos, a exemplo das dificuldades de navegação nos sites de grandes organizações devido ao design não intuitivo (Patterson et al., 2019) e das interfaces difíceis e sites com mau funcionamento (Bernard et al., 2019).
} 


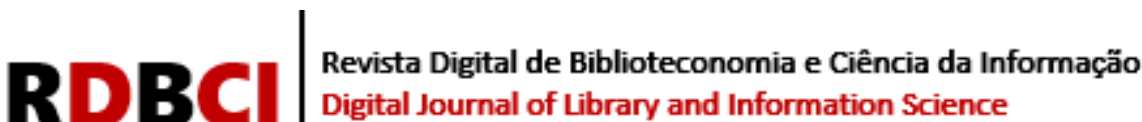

as múltiplas barreiras que impedem o aproveitamento das mídias sociais nas práticas de informação em saúde. Além disso, essa malha oferece caminhos às estratégias informacionais alternativas a serem desenvolvidas no âmbito das mídias sociais para fins de superação e ressignificação das barreiras enfrentadas no processo de transição dos contextos de saúde. Para os estudos futuros, sugere-se ampliar as meta-barreiras que agrupam e relacionam a malha.

\section{CONSIDERAÇÕES FINAIS}

As plataformas de mídia social, embora facilitem o acesso e o compartilhamento de informações sobre saúde para usuários leigos ou pacientes, imprimem dificuldades aos processos de autogerenciamento das informações, autocuidados e tomada de decisões. Essas dificuldades resultam da articulação entre as dificuldades associadas às dinâmicas das plataformas digitais e às dificuldades que emergem dos contextos de transição de saúde.

Compreender essas dificuldades, portanto, não consiste em tarefa simples, pois envolve múltiplas e complexas dimensões que perpassam a materialidade das plataformas. Nesse sentido, a análise focada nas barreiras se configura como estratégia alternativa para desvelar ou alcançar as camadas subjacentes relacionadas ao uso das mídias sociais para fins de informação em contextos de saúde. Nesta revisão, demonstramos que as barreiras percebidas pelos usuários leigos, identificadas a partir da literatura, constituem e conectam uma malha composta por meta-barreiras: diaspórica, desinformação, letramento, interação, emocionais.

Esta malha indica que o uso benéfico das mídias sociais para fins de informação sobre saúde pressupõe a superação dessas barreiras - e de outras possíveis - durante as práticas situacionais de transição dos contextos de saúde. Ou seja, não se trata de enfrentar uma barreira específica, mas toda a malha. Nesse sentido, as intervenções de informação sobre saúde a reboque das mídias sociais devem considerar a incidência relacional dessas barreiras para a promoção da resiliência informacional. Acreditamos que essas intervenções digitais devem articular as práticas situacionais e colaborativas entre os sujeitos que enfrentam experiências comuns com a mediação contingencial de especialistas e/ou profissionais de saúde.

Esperamos que os resultados desta revisão sejam úteis para pesquisadores e profissionais envolvidos com a temática da informação em saúde nas mídias sociais. Esperamos que as barreiras apresentadas, justapostas com outras barreiras estruturais particulares ${ }^{3}$, possam ser consideradas como ponto de partida para outras análises relacionadas com os novos desafios informacionais impostos a partir de março de 2020, decorrentes da pandemia de COVID-19.

\footnotetext{
${ }^{3}$ Os contextos socioculturais, políticos e econômicos podem impactar a forma como os sujeitos lidam com as barreiras. Sendo assim, é pertinente a realização de estudos empíricos no contexto brasileiro ora marcado pela disputa da informação entre diferentes atores, tais como políticos, mídia, mercado, influenciadores, etc.
} 


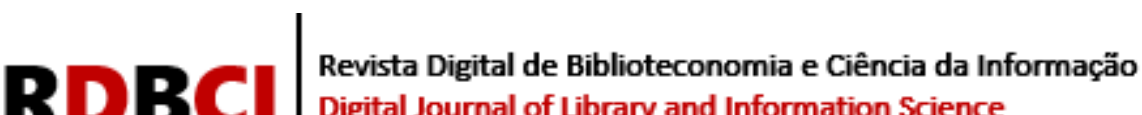 \\ Digital Journal of Library and Information Science}

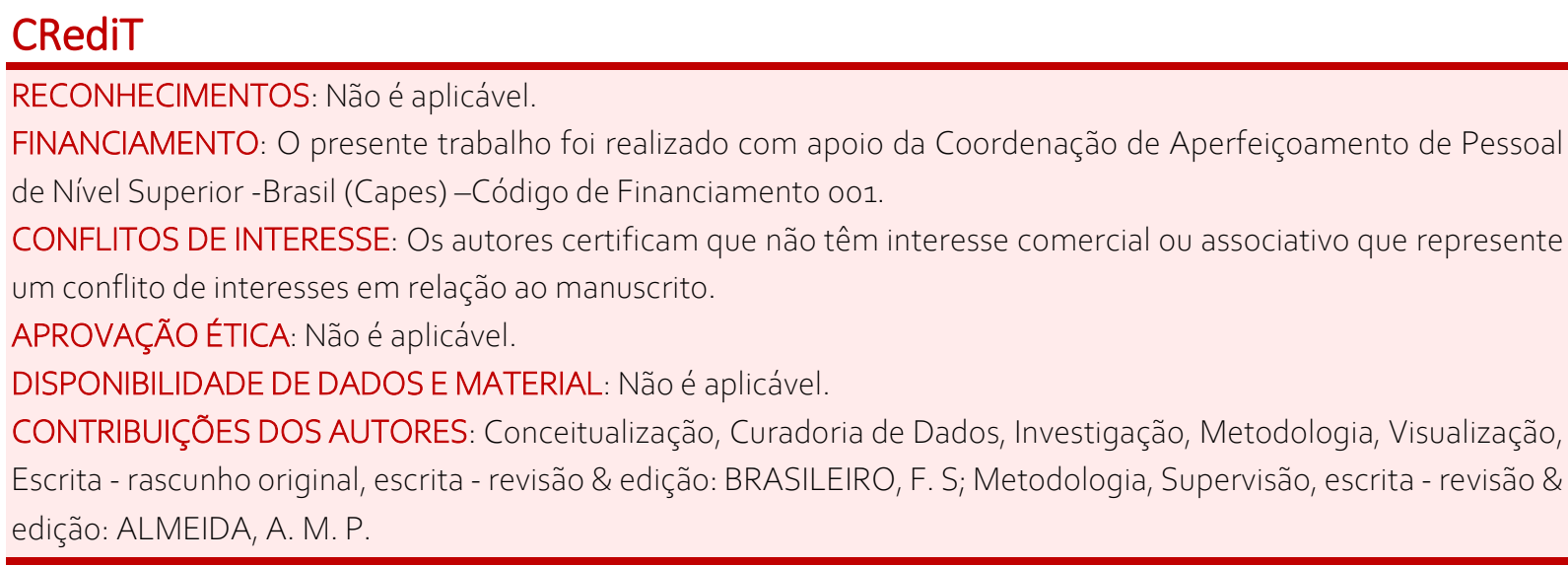

\section{REFERÊNCIAS}

AGARWAL, Nitin; YILIYASI, Yusuf. Information quality challenges in social media. International Conference on Information Quality (ICIQ 2010), Little Rock, Arkansas, 2010.

ALZAHRANI, Amal; ALANZI, Turki. Social media use by people with diabetes in saudi arabia: A survey about purposes, benefits and risks. Diabetes, Metabolic Syndrome and Obesity: Targets and Therapy, v. 12, p. 2363-2372, 2019. Disponível em: https://doi.org/10.2147/DMSO.S208141

ANTHEUNIS, Marjolijin L.; TATES, Kiek.; NIEBOER, Theodoor. E. Patients' and health professionals' use of social media in health care: Motives, barriers and expectations. Patient Education and Counseling, v. 92, n. 3, p. 426-431, 2013. Disponível em: https://doi.org/10.1016/j.pec.2013.06.020

ARAÚJO, Eliany Alvarenga de. Práticas informacionais em ambientes de infodemias: reflexões para o estudo de patologias informacionais. Liinc Em Revista, v. 17, n. 1, e5700, 2021. Disponível em: http://revista.ibict.br/liinc/article/view/5700

BERNARD, Renaldo; SABARIEGO, Carla; CIEZA, Alarcos. Difficulties encountered by people with depression and anxiety on the web: Qualitative study and web-based expert survey. Journal of Medical Internet Research, v. 21, n. 10, 2019. Disponível em: https://doi.org/10.2196/12514

BISSONNETTE-MAHEUX, Véronique; PROVENCHER, Veronique; LAPOINTE, Annie; DUGRENIER, Marilyn; DUMAS, Audrée-Anne.; PLUYE, Pierre; STRAUS, Sharon; GAGNON, Marie-Pierre; DESROCHES, Sophie. Exploring women's beliefs and perceptions about healthy eating blogs: A qualitative study. Journal of Medical Internet Research, v. 17, n.4, 2015. Disponível em: https://doi.org/10.2196/jmir.3504

BIXTER, Michael T.; BLOCKER, Kenneth A.; MITZNER, Tracy L.; PRAKASH, Akanksha; ROGERS, Wendy A. Understanding the use and non-use of social communication technologies by older adults: A qualitative test and extension of the UTAUT model. Gerontechnology, v. 18, n. 2, p.70-88, 2019. Disponível em: 


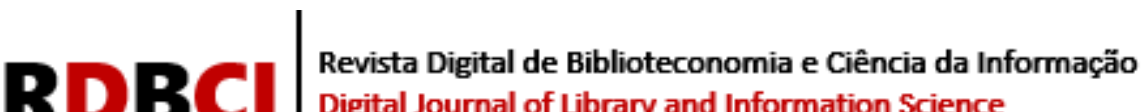 Digital Journal of Library and Information Science}

https://doi.org/10.4017/gt.2019.18.2.002.00

BRASHERS, Dale E.; GOLDSMITH, Daena J.; HSIEH, Elaine. Information Seeking and Avoiding in Health Contexts. Human Communication Research, v. 28, n.2, p. 258-271, 2002. Disponível em: https://doi.org/10.1111/j.1468-2958.2002.tb00807.x

BRASILEIRO, Fellipe Sá. Resiliência informacional em redes sociais virtuais: práticas colaborativas, emoções e mobilidade. Editora UFPB, 2019.

BRASILEIRO, Fellipe Sá. Emoções e redes colaborativas na resiliência informacional. Liinc Em Revista, v. 16, n.2, e5309, 2020. Disponível em: https://doi.org/10.18617/liinc.v16i2.5309

BRASILEIRO, Fellipe Sá; FREIRE, Gustavo Henrique de Araújo. O marketing e a arquitetura da informação para web no contexto do processo de mediação da informação.

Biblionline, v. 8, n. esp., p. 161-174, 2012. Disponível em: https://periodicos.ufpb.br/ojs/index.php/biblio/article/view/14200/8106

CLEMENS, Rachael Green; CUSHING, Amber L. Beyond everyday life: Information seeking behavior in deeply meaningful and profoundly personal contexts. Proceedings of the American Society for Information Science and Technology, v. 47, n. 1, p. 1-10, 2010. Disponível em: https://doi.org/10.1002/meet.14504701228

COLLINS, Randall. Interaction Ritual Chains. Princeton, 2004. Disponível em: https://muse.jhu.edu/book/36737

DE MARTINO, Ivan; D’APOLITO, Rocco; MCLAWHORN, Alexander S; FEHRING, Keith. A.; SCULCO, Peter K.; GASPARINI, Giorgio. Social media for patients: benefits and drawbacks. Current Reviews in Musculoskeletal Medicine, v. 10, n.1, p. 141-145, 2017. Disponível em: https://doi.org/10.1007/s12178-017-9394-7

ESMAEILZADEH, Somayeh; ASHRAFI-RIZI, Hasan; SHAHRZADI, Leila; MOSTAFAVI, Friozeh. A survey on adolescent health information seeking behavior related to high-risk behaviors in a selected educational district in Isfahan. PLoS ONE, v. 13, n. 11, 2018. Disponível em: https://doi.org/10.1371/journal.pone.0206647

GLIK, Deborah; MASSEY, Philip; GIPSON, Jessica; DIENG, Thierno; RIDEAU, Alexandre; PRELIP, Michael. Health-related media use among youth audiences in Senegal. Health Promotion International, v. 31, n.1, p. 73-82, 2016. Disponível em: https://doi.org/10.1093/heapro/dau060

GOFFMAN, Erving. Interaction ritual: essays on face-to-face behavior. Doubleday, 1967.

GOLDSMITH, Daena J. A Normative Approach to the Study of Uncertainty and Communication. Journal of Communication, v. 51, n.3, p. 514-533, 2001. Disponível em: https://doi.org/10.1111/j.1460-2466.2001.tb02894.x

GONZÁLEZ DE GÓMEZ, Maria Nélida. Novas fronteiras tecnológicas das ações de informação: questões e abordagens. Ciência Da Informação, v. 33, n.1, p. 55-67, 2004. 


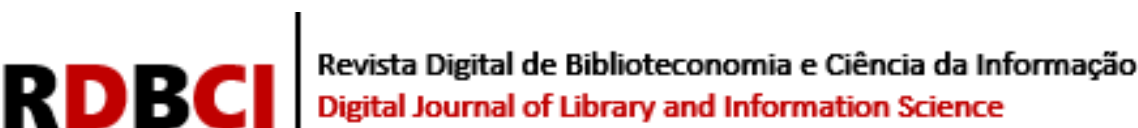

Disponível em: https://doi.org/10.1590/s0100-19652004000100007

GONZÁLEZ DE GÓMEZ, Maria Nélida. Regime de informação: construção de um conceito. Informacao e Sociedade, v.22, n.3, p. 43-60, 2012. Disponível em: https://doi.org/10.22478/ufpb.1981-0695.2018v13n2.43230

HICKS, Alison; LLOYD, Annemaree. It takes a community to build a framework: Information literacy within intercultural settings. Journal of Information Science, v. 42, n. 3, p. 334-343, 2016. Disponível em: https://doi.org/10.1177/0165551510000000

JOHNSON, J. David; CASE, Donald Owen. Health information seeking. Peter Lang, 2012.

KARLOVA, Natascha A.; FISHER, Karen E. A social diffusion model of misinformation and disinformation for understanding human information behaviour. Information Research, v. 18, n. 1, 2013.

KARLOVA, Natascha A.; LEE, Jin Ha. Notes from the underground city of disinformation: A conceptual investigation. Proceedings of the American Society for Information Science and Technology, v. 48, n. 1, p. 1-9, 2011. Disponível em: https://doi.org/10.1002/meet.2011.14504801133

LIAO, Yuting. Sharing personal health information on social media: Balancing selfpresentation and privacy. ACM International Conference Proceeding Series, p. 194-204, 2019. Disponível em: https://doi.org/10.1145/3328529.3328560

LLOYD, Annemaree. Framing information literacy as information practice: Site ontology and practice theory. Journal of Documentation, v. 66, n.2, p.245-258, 2010. Disponível em: https://doi.org/10.1108/00220411011023643

LLOYD, Annemaree. Building Information Resilience: How do Resettling Refugees Connect with Health Information in Regional Landscapes - Implications for Health Literacy. Australian Academic and Research Libraries, v. 45, n.1, p. 48-66, 2014. Disponível em: https://doi.org/10.1080/00048623.2014.884916

LLOYD, Annemaree. Stranger in a strange land; enabling information resilience in resettlement landscapes. Journal of Documentation, v. 71, n. 5, p. 1029-1042, 2015. Disponível em: https://doi.org/10.1108/JD-04-2014-0065

MCKENZIE, Pamela. J. A model of information practices A model of information practices in accounts of everyday-life information seeking. Journal of Documentation, v. 59, n. 1, 2003. Disponível em: https://doi.org/10.1108/00220410310457993

MOHER, David; LIBERATI, Alessandro; TETZLAFF, Jennifer; ALTMAN, Douglas G. Preferred reporting items for systematic reviews and meta-analyses: The PRISMA statement. British Medical Journal Publishing Group v. 339, p. 332-336, 2009. Disponível em: https://doi.org/10.1136/bmj.b2535

MOULT, Alice; BURROUGHS, Heather; KINGSTONE, Tom; CHEW-GRAHAM, Carolyn A. How older adults self-manage distress - Does the internet have a role? A qualitative study. 


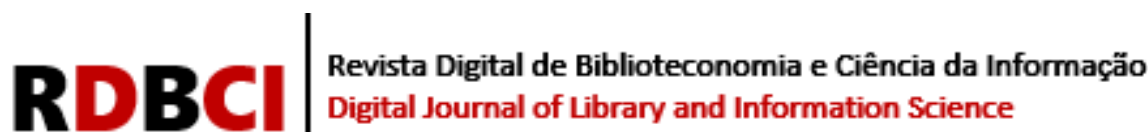

BMC Family Practice, v. 19, n. 1, 2018. Disponível em: https://doi.org/10.1186/s12875-018$\underline{0874-7}$

NISAR, Sobia; SHAFIQ, Muhammad. Framework for efficient utilisation of social media in Pakistan's healthcare sector. Technology in Society, v. 56, p. 31-43, 2019. Disponível em: https://doi.org/10.1016/j.techsoc.2018.09.003

OXFORD. The Oxford English Dictionary (J. Simpson \& E. Weiner (eds.)). Oxford University Press, 2017. Disponível em: https://global.oup.com/academic/product/the-oxfordenglish-dictionary-9780198611868?cc=gb\&lang=en\&

PATTERSON, Susan Patricia; HILTON, Shona, FLOWERS, Paul; MCDAID, Lisa M. What are the barriers and challenges faced by adolescents when searching for sexual health information on the internet? Implications for policy and practice from a qualitative study.

Sexually Transmitted Infections, v. 95, n. 6, p. 462-467, 2019. Disponível em: https://doi.org/10.1136/sextrans-2018-053710

RUPPEL, Emily H.; KARPMAN, Hannah E.; DELK, Carolyn E.; MERRYMAN, Mallory. Online maternity information seeking among lesbian, bisexual, and queer women.

Midwifery, v. 48, p. 18-23, 2017. Disponível em: https://doi.org/10.1016/j.midw.2017.02.011

SCHATZKI, Theodore. R. Peripheral Vision The Sites of Organizations. Organization Studies, v. 26, n.3, p. 465-484, 2005. Disponível em: https://doi.org/10.1177/0170840605050876

SOUSA, Andreia Pinto de; ALMEIDA, Ana Margarida Pisco. Trust and Credibility Perception in E-Health: Interface Contributions. In M. M. Cruz-Cunha, I. M. Miranda, R. Martinho, \& R. Rijo (Eds.), Encyclopedia of E-Health and Telemedicine, p. 1105-1122, 2016. Disponível em: https://doi.org/10.4018/978-1-4666-9978-6

STAHL, Bernd. Carsten. On the difference or equality of information, misinformation, and disinformation: A critical research perspective. Informing Science, 9, 83-96, 2006. Disponível em: https://doi.org/10.28945/473

WANG, Yuxi; MCKEE, Martin; TORBICA, Aleksandra; STUCKLER, David Systematic Literature Review on the Spread of Health-related Misinformation on Social Media. In Social Science and Medicine, v. 240, p. 112552, 2019. Disponível em: https://doi.org/10.1016/j.socscimed.2019.112552

WITZEL, T. Charles.; GUISE, Andy; NUTLAND, Will; BOURNE, Adam. It Starts with Me: Privacy concerns and stigma in the evaluation of a Facebook health promotion intervention. Sexual Health, v. 13, n. 3, n. 228-233, 2016. Disponível em: https://doi.org/10.1071/SH15231 


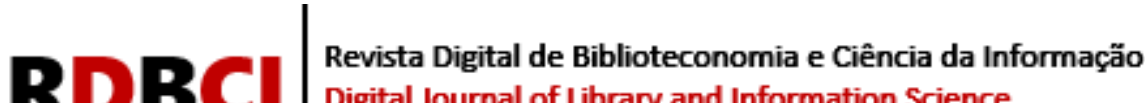 \\ Digital Journal of Library and Information Science}

